\title{
Standardised measurement of physical capacity in young and middle-aged active adults with hip-related pain: recommendations from the first International Hip-related Pain Research Network (IHiPRN) meeting, Zurich, 2018
}

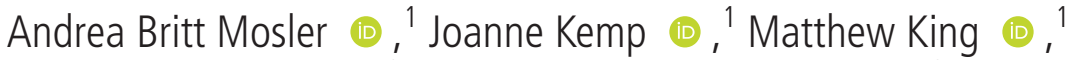 \\ Peter R Lawrenson (1) ${ }^{2}$ Adam Semciw, ${ }^{1}$ Matthew Freke, ${ }^{2}$ Denise M Jones, ${ }^{1}$

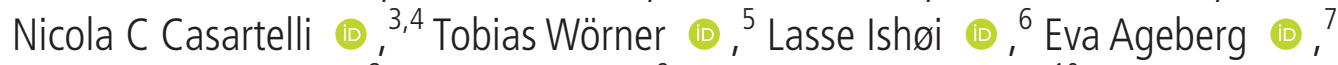 \\ Laura E Diamond $0^{8}{ }^{8}$ Michael A Hunt, ${ }^{9}$ Stephanie Di Stasi (1) ${ }^{10}$ \\ Michael P Reiman (1) , ${ }^{11}$ Michael Drew, ${ }^{12}$ Daniel Friedman, ${ }^{13}$ Kristian Thorborg (1) , \\ Michael Leunig, ${ }^{14}$ Mario Bizzini, ${ }^{15}$ Karim M Khan 다, ${ }^{16}$ Kay M Crossley (1) , ${ }^{1}$ \\ Rintje Agricola, ${ }_{1}^{17}$ Nancy Bloom, ${ }^{18,19}$ Hendrik Paul Dijkstra, ${ }_{1}^{20,21}$ Damian Griffin, 22,23

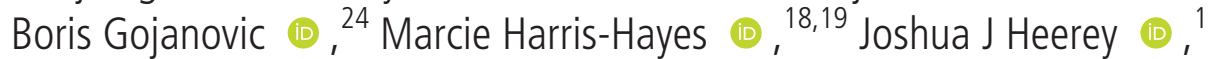 \\ Per Hölmich, ${ }^{6}$ Franco M Impellizzeri (1) , ${ }^{25}$ Ara Kassarjian, ${ }^{26}$ \\ Kristian Marstrand Warholm (1), ${ }^{27}$ Sue Mayes, ${ }^{1,28}$ Håvard Moksnes, ${ }^{29}$ \\ May Arna Risberg, ${ }^{30,31}$ Mark J Scholes 나, ${ }^{1}$ Andreas Serner (10, ${ }^{20}$ Pim van Klij, ${ }^{17}$ \\ Cara L Lewis
}

- Additional material is published online only. To view please visit the journal online (http://dx.doi.org/10.1136/ bjsports-2019-101457).

For numbered affiliations see end of article.

Correspondence to Dr Andrea Britt Mosler, La Trobe Sport and Exercise Medicine Research Centre, La Trobe University College of Science Health and Engineering, Bundoora, VIC 3086, Australia; abmosler@hotmail.com

Accepted 17 November 2019 Published Online First 19 December 2019

Check for updates

(C) Author(s) (or their employer(s)) 2020. No commercial re-use. See rights and permissions. Published by BMJ.

To cite: Mosler AB, Kemp J, King $\mathrm{M}_{\text {, et }}$ al. Br I Sports Med 2020:54:702-710.

\section{ABSTRACT}

Hip-related pain can significantly impact quality of life, function, work capacity, physical activity and family life. Standardised measurement methods of physical capacity of relevance to young and middleaged active adults with hip-related pain are currently not established. The aim of this consensus paper was to provide recommendations for clinical practice and research on standardised measurement methods of physical capacity in young and middle-aged active adults with hip-related pain. Four areas of importance were identified: (1) clinical measures (range of motion, muscle strength, functional impairments), (2) laboratory-based measures (biomechanics and muscle function (muscle activity, size and adiposity)), (3) physical activity, and (4) return to sport/performance. The literature was reviewed, and a summary circulated to the working group to inform discussion at the consensus meeting. The working group developed clinical and research recommendations from the literature review, which were further discussed and modified within the working group at the consensus meeting. These recommendations were then presented to all 38 International Hip-related Pain Research Network (IHiPRN) participants for further discussion, refinement and consensus voting. Therefore, the recommendations voted on were based on a combination of current evidence and expert opinion. The consensus meeting voted on 13 recommendations, six of which were clinically orientated, and seven more research specific. We recommended that clinicians working with young and middle-aged active adults with hip-related pain assess strength using objective methods of measurement, and clinically assess performance of functional tasks, including walking and running. Physical activity should be quantified using both self-reported and objective measures, and patient expectations of recovery should be quantified prior to treatment. It was recommended that return to physical activity (including sport and occupation) be quantified, and sport-specific activities should be assessed prior to return to sport. The IHiPRN participants were uncertain regarding recommendations for range of motion assessment. Research recommendations were that the measurement properties of range of motion, strength and functional performance tests be investigated, reported and improved in both clinical and research settings. Reporting of movement-related parameters (biomechanics and muscle function) should be standardised and the relationship among movement-related parameters, symptoms, function, quality of life, and intra-articular and imaging findings should be investigated. Quantification of return to physical activity (including sport and occupational demands) is required in future research, and the return to sport continuum should be used. Future research is required to determine the best criteria for rehabilitation progression and return to physical activity following hip-related pain management.

\section{INTRODUCTION}

Hip-related pain is a major cause of disability, significantly impacting quality of life, function, work capacity and family life. ${ }^{1}$ It is frequently seen in young and middle-aged active adults, with the psychological and physical impact occurring at a time when major work and life responsibilities are experienced. ${ }^{1-4}$ The most common causes of 
hip-related pain in young and middle-aged active adults are: femoroacetabular impingement (FAI) syndrome, dysplasia and intra-articular pathology (labral tears, chondral damage and ligamentum teres tears) without bony morphological variant (Reiman et al, 2019). ${ }^{5}$ High economic burden can result from hip-related pain, ${ }^{6}$ emphasising the need for early detection and effective management of this musculoskeletal condition.

Minimal reporting standards for clinical research on groin pain in athletes were recently published, aiming to allow comparison of outcome measures across studies, and facilitate data synthesis for systematic reviews and meta-analyses. ${ }^{7}$ The importance of using clinical measures that are quantifiable, reliable and valid in both clinical practice and research was emphasised in this paper. Standardised methods for measuring physical capacity relevant to young and middle-aged active adults with hip-related pain are currently not established. Subsequently, heterogeneity in measurement methods used, and reporting of these methods, has prevented meta-analyses in many recently published systematic reviews. ${ }^{8-13}$ This limits the ability to compare and collectively evaluate research findings, and provide recommendations to clinical practice. Consensus on standardised measurement methods that identify impairments and functional limitations, inform progression of rehabilitation and evaluate the efficacy of evidence-based, physiotherapist-led, interventions (non-surgical, pre/postsurgical) in young and middle-aged active adults with hip-related pain is essential for progression of the field.

In 2016, the International Hip-related Pain Research Network (IHiPRN) was developed in response to a need to collaborate across research groups and disciplines, and to disseminate knowledge of hip pain to clinicians. The focus of the IHiPRN specifically relates to 'Hip-related pain in young and middleaged active adults'. The aim of this consensus paper was to provide recommendations for clinical practice and research on standardised measurement methods of physical capacity in young and middle-aged active adults with hip-related pain.

\section{METHODS}

Background and process of the consensus meeting

The IHiPRN leadership group (JK, KMC, MB, ABM, CLL and KMK) met in January 2017 to identify potential expert group members. Experts were selected based on their track record of publications and being current active researchers in the field of hip-related pain in young and middle-aged adults. Researchers who were also clinicians in the field were viewed favourably. Potential expert group members were contacted via email asking them to express interest in taking part in the first IHiPRN consensus meeting in Zurich in November 2018. Potential expert group members were also asked to identify other experts for invitation that the leadership group may not have identified.

Following this expression of interest, four key areas were identified as priorities for consensus. These four key areas were:

I. Classification of hip pain (including use of (1) clinical tests; and (2) imaging).

II. Patient-reported outcome measures for hip pain (including hip-related measures, and maybe others including pain/ coping/fear/utility measures).

III. Standardised measurement of physical capacity in hiprelated pain (including clinical measures, biomechanics, electromyography, physical activity, functional performance and return to sport (RTS)).

IV. Physiotherapist-led treatment of hip-related pain.

The leadership group then identified experts to lead each of the four working groups. These were MR and RA (group 1),
Box 1 Four areas of importance for standardised measurement methods of physical capacity for hip-related pain

1. Clinical measures (range of motion, muscle strength, and functional performance).

2. Laboratory-based measures (biomechanics and muscle function (muscle activity, size and adiposity)).

3. Measures of physical activity.

4. Return to physical activity (including sport and occupational demands).

FMI and JK (group 2), ABM and CLL (group 3) and JK and MB (group 4). Members of each working group were then determined following discussion between the leadership group and the working group leaders.

\section{Expert group selection}

All consensus meeting participants were considered experts and at the time of meeting were actively researching in the field of hip-related pain in young and middle-aged active adults. Areas of expertise among the participants included physiotherapy, orthopaedic surgery, sport and exercise medicine, biomechanics, diagnostics, imaging and radiology, patient-reported outcome measures and exercise science. In addition, many of the participants were also expert clinicians who regularly treat young and middle-aged active adults with hip-related pain.

\section{Preagreement meeting process}

Prior to the meeting, the four working groups prepared evidence summaries for each of the four key areas for consensus. The working group formed for key area 3: standardised measurement of physical capacity in hip-related pain, constituted 21 IHiPRN participants with particular expertise in measuring physical capacity in young and middle-aged active adults with hip-related pain. Four main areas were identified in which standardised measurement methods of physical capacity were deemed important for clinical practice and research on hiprelated pain (box 1).

Current evidence in these four areas was summarised following a review of the literature. The evidence summary document was distributed and revised by the working group members to identify the specific areas requiring consensus and inform the IHiPRN participants. Multiple revisions of this evidence summary were conducted by the working group, prior to a final draft being confirmed. Based on this literature summary, preliminary clinical and research recommendations were developed, revised within the working group and circulated to all IHiPRN participants via email at least 1 week prior to the consensus meeting in Zurich.

\section{Agreement meeting process}

At the beginning of the face-to-face meeting in Zurich, small breakout working groups discussed, revised and refined the preliminary clinical and research recommendations. The leaders of the working group (ABM and CLL) then presented the evidence summary and revised recommendations to all 38 IHiPRN participants. Each consensus recommendation was then discussed, revised and refined by the 38 IHiPRN participants present at the consensus meeting.

At the conclusion of the discussion, each participant was asked to vote on the recommendation. Participants were instructed to synthesise the evidence summaries presented with their expert 
knowledge when casting their vote. Participants were blinded to each other's scoring and a 10-point Likert scale was used to score each recommendation, where 0 was considered to be 'inappropriate' and 9 'appropriate' as previously described. ${ }^{14} 15$ Scores were pooled and the median (IQR) for each recommendation was determined. Recommendations with median scores that were 0-3 were considered inappropriate, scores 4-6 were considered uncertain and scores 7-9 were considered appropriate. $^{1415}$ The consensus recommendations presented in this paper are based on the evidence available at the time of the meeting, refined through the discussion of the IHiPRN participants and combined with the pooled voting score for that recommendation.

\section{RESULTS}

\section{Expert group demographics}

The consensus meeting in Zurich, Switzerland, on 17 and 18 November 2018 was attended by 37 participants. Six participants were not able to attend in person, and one attended the meeting via videoconferencing. As such, 38 participants were involved in the consensus voting process. The expert group of 27 physiotherapists, 7 orthopaedic surgeons, 4 sport and exercise medicine physicians, 4 exercise scientists, 1 radiologist and 1 general medical doctor included 12 women and 32 men. The mean (SD) age of participants was 41 (11) years and the mean (SD) number of years' experience was 20 (10) years. Twenty-one participants were from Europe, 13 from Australia/New Zealand, 8 from North America and 2 from the Middle East. All participants were fluent English speakers, and no translation services were required. Areas of expertise within the delegates included physiotherapy, orthopaedic surgery, sport and exercise medicine, biomechanics, diagnostics, imaging and radiology, patientreported outcome measures and exercise science.

\section{Results of the consensus meeting}

The literature summary used in this consensus process can be accessed in the online supplementary appendix. Six clinical recommendations and seven research recommendations were voted on by the 38 IHiPRN participants. These final recommendations and the results of the consensus voting are presented in table 1 . The IHiPRN participants determined all recommendations to be appropriate, except for one. The clinical recommendation regarding measurement of range of motion was determined to be uncertain.

The median scores (IQR) for the 13 recommendations ranged from $6^{3}$ points to $9^{1}$ points. The spread of the voting scores for each recommendation is presented in figure 1 (clinical recommendations) and figure 2 (research recommendations).

\section{DISCUSSION}

The aim of the first IHiPRN consensus meeting was to provide clinical and research recommendations for standardised measurement methods of physical capacity in young and middleaged active adults with hip-related pain. The recommendation on clinical measurement of hip range of motion was considered uncertain, and all other recommendations were considered appropriate by the IHiPRN participants. The clinical and research recommendations which were based on current evidence, expert opinion and consensus voting of the IHiPRN participants are discussed below.

\section{Clinical recommendations \\ Clinical measures}

Range of motion

Clinical recommendation 1: Hip range of motion can be measured clinically using a goniometer or inclinometer; however, the optimal methods of measurement (eg, active vs

\begin{tabular}{|c|c|c|c|c|c|}
\hline \multicolumn{2}{|c|}{ Clinical recommendations } & \multirow{2}{*}{$\begin{array}{l}\text { Median } \\
6\end{array}$} & \multirow{2}{*}{$\frac{\mathrm{IQR}}{5-8}$} & \multirow{2}{*}{$\frac{\text { Mode }}{6}$} & \multirow{2}{*}{$\begin{array}{l}\text { Consensus voting result } \\
\text { Uncertain }\end{array}$} \\
\hline $\mathrm{C1}$ & $\begin{array}{l}\text { Hip range of motion can be measured clinically using a goniometer or inclinometer; however, the optimal methods of } \\
\text { measurement (eg, active vs passive; appropriate positions and stabilisation methods) are currently unknown. }\end{array}$ & & & & \\
\hline $\mathrm{C} 2$ & $\begin{array}{l}\text { People with hip-related pain demonstrate lower strength in hip adduction, abduction, flexion, internal rotation } \\
\text { and external rotation compared with individuals without pain; measuring strength using objective methods is } \\
\text { recommended. }\end{array}$ & 8 & $7-9$ & 9 & Appropriate \\
\hline $\mathrm{C} 3$ & $\begin{array}{l}\text { People with hip-related pain demonstrate impaired performance during functional tasks; therefore, performance of } \\
\text { functional tasks should be assessed clinically. }\end{array}$ & 8 & $7-9$ & 9 & Appropriate \\
\hline C4 & $\begin{array}{l}\text { Physical activity should be measured using objective methods in people with hip-related pain and can be combined } \\
\text { with self-reported measures of physical activity to capture different dimensions. }\end{array}$ & 7 & $5-8$ & 9 & Appropriate \\
\hline $\mathrm{C5}$ & $\begin{array}{l}\text { Clinicians should quantify patient expectations regarding their return to physical activity (including: sport level, } \\
\text { sporting performance and occupation). }\end{array}$ & 8 & $7-9$ & 9 & Appropriate \\
\hline C6. & Sport-specific activities should be assessed to guide return to sport. & 8 & $7-9$ & 8 & Appropriate \\
\hline \multicolumn{2}{|c|}{ Research recommendations } & Median & IQR & Mode & Recommendation \\
\hline R1 & $\begin{array}{l}\text { Further research should investigate, report and improve the measurement properties of tests of range of motion, } \\
\text { muscle strength and functional performance. }\end{array}$ & 9 & $8-9$ & 9 & Appropriate \\
\hline $\mathrm{R} 2$ & $\begin{array}{l}\text { Future research is needed to investigate the relationship among movement-related parameters (biomechanics, } \\
\text { muscle function), symptoms, function, quality of life, and imaging and intra-articular findings. }\end{array}$ & 8 & $6-9$ & 9 & Appropriate \\
\hline R3 & $\begin{array}{l}\text { Established minimum reporting standards for movement-related parameters (eg, biomechanics, muscle function) } \\
\text { should be followed, or determined as appropriate. }\end{array}$ & 8 & 7-9 & 9 & Appropriate \\
\hline R4 & $\begin{array}{l}\text { The patient's goals and expectations, physical activity and occupational requirements should be measured using } \\
\text { quantitative and qualitative methods. }\end{array}$ & 9 & $8-9$ & 9 & Appropriate \\
\hline R5 & $\begin{array}{l}\text { The return to sport (RTS) continuum recommended by the } 2016 \text { RTS consensus paper should be used in future } \\
\text { research. }\end{array}$ & 9 & $8-9$ & 9 & Appropriate \\
\hline R6 & $\begin{array}{l}\text { Future research is required to quantify, and report return to physical activity (including sport and occupation) } \\
\text { following management of hip-related pain. }\end{array}$ & 9 & $8-9$ & 9 & Appropriate \\
\hline R7 & $\begin{array}{l}\text { Research to determine the best criteria for rehabilitation progression and RTS following management of hip-related } \\
\text { pain is recommended. }\end{array}$ & 9 & $8-9$ & 9 & Appropriate \\
\hline
\end{tabular}




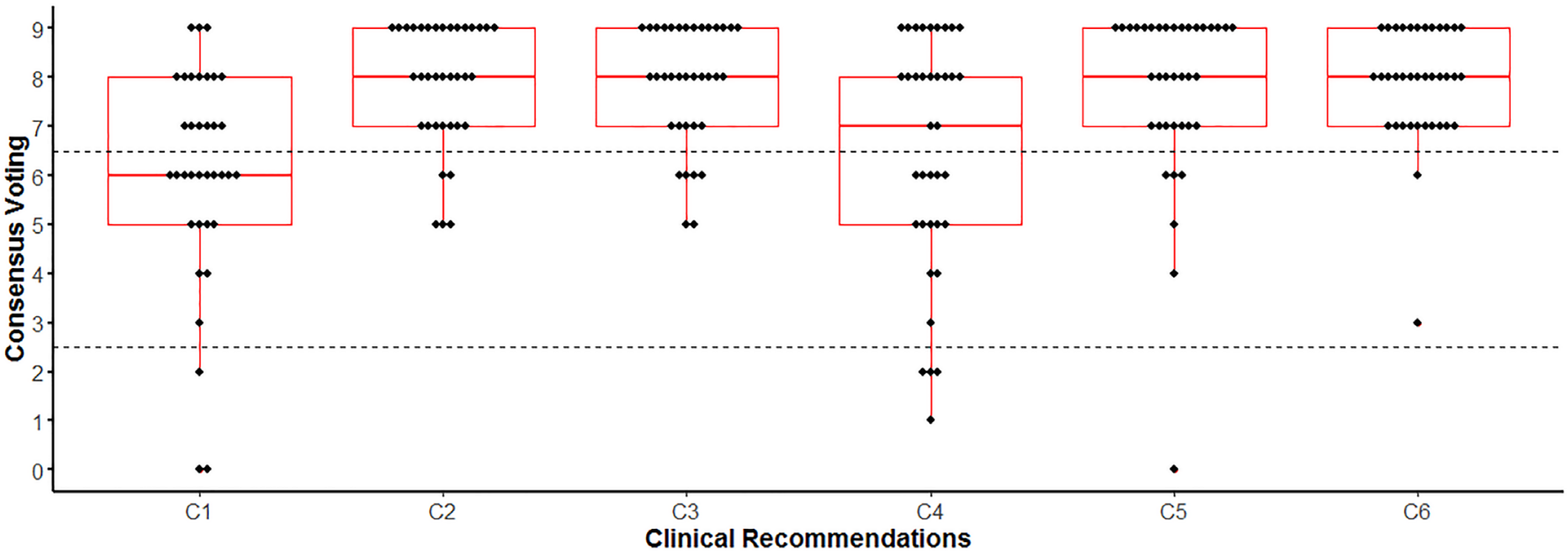

Figure 1 Spread of the consensus voting scores for each of the clinical recommendations. C, clinical recommendation.

passive; appropriate positions and stabilisation methods) are currently unknown.

There is conflicting evidence whether range of motion differs between individuals with and without hip-related pain. ${ }^{8-12} 1617$ The heterogeneity in both the classification of patients with hiprelated pain, ${ }^{2} 18$ and measurement methods described in the studies included in these systematic reviews, contributes to this conflicting evidence. ${ }^{8-12} 16$ The ambiguity of findings in the literature synthesis, and paucity of studies investigating the clinimetric properties of range of motion measurement methods, was reflected in the wide range of scores (0-9) for this recommendation (box 1 and figure 1).

The IHiPRN participants discussed whether the recommended measurement methods may differ depending on the purpose of the measurement. For example, different methods of measuring range of motion may be appropriate when assisting in the clinical diagnosis of hip dysplasia, compared with baseline screening of an elite athlete, or to determine the efficacy of an intervention. The conflicting evidence and the result of the consensus vote suggest that it is currently unclear whether it is even relevant to measure range of motion in the clinical management of patients with hip-related pain (figure 1). Furthermore, the optimal methods of measuring range of motion for hip-related pain are not currently established. The IHiPRN participants suggested that methods with the highest clinimetric properties be chosen by clinicians, but also be tailored to the purpose of the assessment and needs of the individual. High-quality research is required that specifically investigates the importance of measuring range of motion in the clinical management of young and middle-aged active adults with hip-related pain.

\section{Muscle strength}

Clinical Rrecommendation 2: People with hip-related pain demonstrate lower strength in hip adduction, abduction, flexion, internal rotation and external rotation compared towith individuals without pain; measuring strength using objective methods of measurement is recommended.

Systematic reviews included in the evidence summary consistently report lower muscle strength for hip adduction, abduction, flexion, internal rotation and external rotation in individuals with hip-related pain compared with individuals without pain. ${ }^{8919}$ However, there is conflicting evidence whether extension strength deficits are found in this population (online supplementary appendix). ${ }^{919}$

Strength measurements acquired using dynamometry (handheld, external load cell or isokinetic devices) have acceptable intrarater reliability, ${ }^{19}$ providing confidence for the clinical utility of strength testing within a single tester. However, evidence is lacking with regard to inter-rater reliability for methods of hip

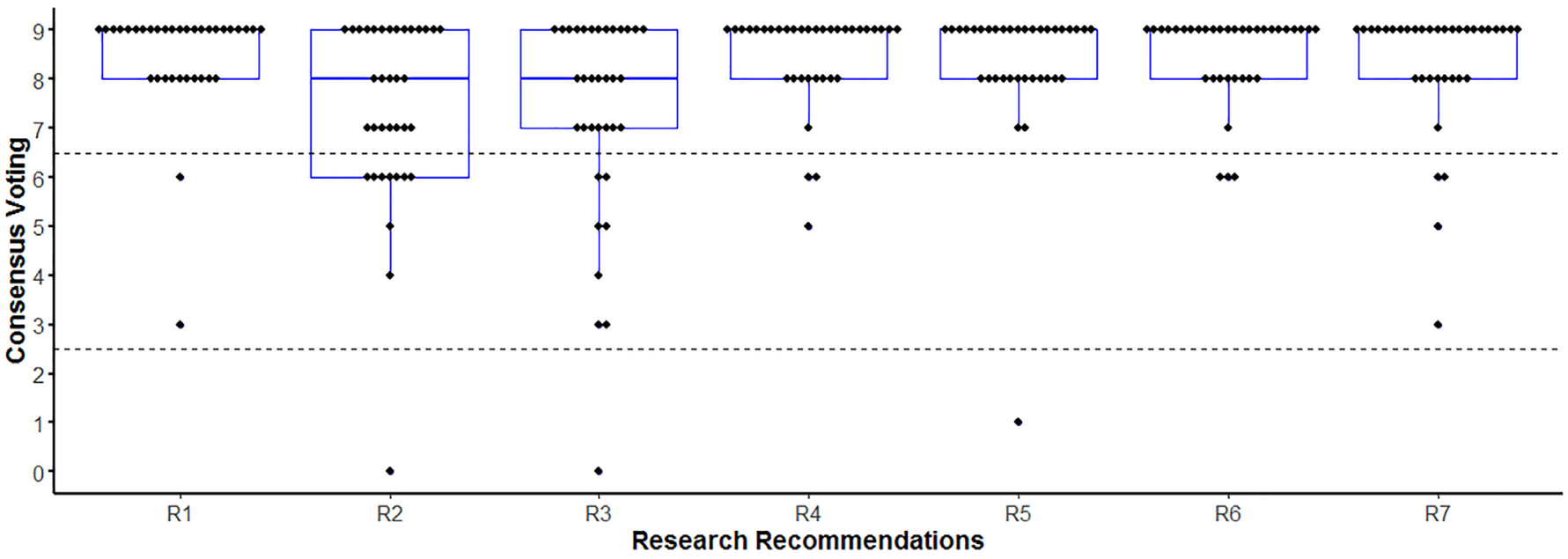

Figure 2 Spread of the consensus voting scores for each of the research recommendations. R, research recommendation. 
strength measurement, and responsiveness of testing methods to measure change (online supplementary appendix). ${ }^{19} 20$ Therefore, we recommend that clinicians use objective methods to measure muscle strength in the assessment and management of hip-related pain. However, the interpretation of these results should consider potential intratester and intertester differences, and instrument measurement error. Either isometric or eccentric testing using a handheld dynamometer is acceptable for clinical and research purposes, but external fixation is recommended for isometric testing using testers of different strength to minimise potential systematic error. ${ }^{21}$

\section{Functional performance}

Clinical recommendation 3: People with hip-related pain demonstrate impaired performance during functional tasks; therefore, performance of functional tasks should be assessed clinically.

Varying methods have been used to assess functional tasks and balance in people with hip-related pain, and the results have been synthesised in several recent systematic reviews. ${ }^{8} 922-24$ The consistent findings were that people with hip-related pain demonstrate reduced squat depth, and impaired performance on single-leg balance tasks and the star excursion balance test (SEBT) (box 1, online supplementary appendix). It is therefore recommended that these tasks be included in the clinical assessment of this patient population. There is limited evidence that the intratester and intertester reliability is acceptable for the SEBT and single-leg standing test, ${ }^{20} 23$ while acceptable intertester reproducibility in the clinic has not been established for the assessment of single-leg squat and step-down tests (box 1, online supplementary appendix).

There is insufficient evidence on the minimal detectable change or standard error of measurement. Therefore, when using these clinical measures, clinicians should acknowledge that the amount of change required to be clinically meaningful is currently unknown.

\section{Measures of physical activity}

Clinical recommendation 4: Physical activity should be quantified using objective methods of measurement in people with hiprelated pain and can be combined with self-reported measures of physical activity in order to capture different dimensions.

Physical activity levels in people with hip-related pain should be measured to determine their baseline activity, fluctuations with symptoms, and change over time, or in response to intervention. Substantial discrepancies exist between self-reported physical activity levels (using self-report questionnaires) and objective methods of measuring physical activity. ${ }^{25}$ Self-report data are hampered by reporting bias, and inadequate reliability and validity compared with objective methods, such as bodyworn accelerometers. ${ }^{26}$ However, the placement, location and design of an accelerometer may limit the type of physical activity that can be captured. ${ }^{27}$ Self-reported measures also capture different dimensions of physical activity than objective measures, ${ }^{2528}$ as well as the person's response to physical activity (eg, muscle soreness, general fatigue, and so on).

Physical activity trackers and smartphone technology may be appropriate for use for people with hip-related pain. ${ }^{26-31}$ Recent advances in technology allow for the easy objective measurement of physical activity in clinic, with commercial devices such as Fitbit demonstrating adequate accuracy, reliability and validity in measuring physical activity levels for both clinical and research purposes. ${ }^{27} 32$ Therefore, the IHiPRN participants recommended that clinicians quantify physical activity using objective measures in the management of hip-related pain in young and middle-aged active adults and also include self-reported measures as appropriate.

\section{Return to physical activity (including sport and occupational} demands)

Clinical recommendation 5: Clinicians should quantify patient expectations regarding their return to physical activity (including: sport level, sporting performance and occupation).

Most patients seeking intervention for hip-related pain wish to return at least to their preinjury physical activity level, which may include sport level and/or performance, and/or occupational demands. For young and middle-aged active adults, this is often one of the reasons they seek help in managing their condition. ${ }^{33-36}$ Management success (both non-surgical and surgical) may be defined by the patient's ability to achieve their preintervention sport or physical activity goals. Preintervention expectations have been found to influence postintervention satisfaction in patients with hip-related pain. ${ }^{36} 37$

Half of patients were shown to be overly optimistic in their expectations for ongoing symptoms, RTS and general physical activity levels following surgery for FAI syndrome, ${ }^{36}$ suggesting discord between expectations and actual outcome for many patients. The IHiPRN participants concluded that clinicians should discuss accurate and balanced information about intervention benefits and harms with patients, providing opportunity to develop realistic expectations and make informed decisions. ${ }^{38}$ To facilitate this process, the IHiPRN participants recommended that patient expectations and goals be quantified at baseline (prior to clinical intervention) and fulfilment of expectations regularly re-evaluated throughout the management process. Patient expectations and their fulfilment can be measured with questionnaires, such as those used previously in patients undergoing spinal surgery, ${ }^{39}$ and with hip-related pain. ${ }^{36}$

Clinical recommendation 6: Sport-specific activities should be assessed to guide RTS.

Ensuring that an athlete has regained optimal physical and psychological function prior to returning to sport is one of the most difficult tasks facing clinicians managing hip-related pain in athletes. Suggested RTS criteria have been previously reported, ${ }^{40-47}$ but currently none have been validated (online supplementary appendix). ${ }^{48} 49$

The 2016 RTS consensus paper recommends including assessments of dynamic agility and of psychological readiness to RTS in standard RTS criteria. ${ }^{34}$ In line with this, the IHiPRN participants recommended that testing for RTS should be sport specific and match the demands of the sport. However, there is currently a lack of evidence to provide specific recommendations on criteria to use for RTS following management of hiprelated pain. The validation of RTS criteria relevant for young and middle-aged active adults with hip-related pain is urgently required.

\section{Research recommendations \\ Clinical measures}

Research recommendation 1: Further research should investigate, report and improve the measurement properties of tests of range of motion, muscle strength and functional performance.

The IHiPRN participants recommended a systematic review on the clinimetric properties of measurement methods for hip range of motion and strength to clearly identify methods with acceptable reliability and low measurement error. These methods should be tested for validity in populations of young and middle-aged active adults with hip-related pain to recommend 
standardised methods for measuring range of motion and muscle strength in clinical practice and research.

Discussion among IHiPRN participants raised multiple areas of uncertainty regarding measurement of hip range of motion. These areas included: the use of active versus passive movements, examination of only pain-free range, optimal stabilisation methods, and whether mechanical devices, such as the hip internal rotation examination chair, ${ }^{50}$ are required to improve accuracy and reliability. The IHiPRN participants also discussed whether side-to-side comparisons in symptomatic individuals were acceptable for research purposes or comparisons be limited to asymptomatic individuals, as the clinical interpretation of differences between symptomatic and asymptomatic limbs is currently unclear. High-quality studies that follow the minimal reporting standards for clinical research are required to clarify these areas of uncertainty. ${ }^{7}$ Specifically, clear diagnostic inclusion criteria for the participants of the study should be reported, and a detailed description provided of all measurement methods (including clinimetric properties) and instruments used in the study.

The literature review provided clearer guidance for standardised methods of measurement of hip muscle strength in people with hip-related pain. ${ }^{19}{ }^{20}$ However, reporting of intertester reliability and measurement error is currently lacking. Therefore, high-quality studies are needed to examine and report the clinimetric properties of measurement methods for hip muscle strength and investigate the validity of strength testing in symptomatic populations.

There was considerable discussion of methods measuring functional performance to be recommended for clinical and research purposes. Since people with hip-related pain demonstrate reduced squat depth and have impaired performance on single-leg balance tasks and the SEBT, these tests are recommended to be included in clinical research in this area. There is limited and conflicting evidence that hopping performance is impaired in this patient population, and further high-quality studies are required to resolve this uncertainty. ${ }^{22}$ Furthermore, the IHiPRN participants also discussed that the methods of assessment of functional performance should be adapted to the population of interest. For example, the examination of running technique may be important for a football player, but less so for a swimmer.

\section{Biomechanics and muscle function}

Research recommendation 2: Future research is needed to investigate the relationship among movement-related parameters (biomechanics, muscle function), symptoms, function, quality of life, and imaging and intra-articular findings.

Evidence suggests that hip biomechanics are altered in multiple planes in individuals with hip-related pain when compared with asymptomatic controls. ${ }^{2451}$ Individuals with FAI syndrome walk with a lower peak hip extension angle, peak internal rotation angle, and external rotation joint torque, and squat to a lesser depth despite no difference in peak hip flexion angle compared with individuals without hip-related pain. ${ }^{24}$ Individuals with developmental hip dysplasia walk with a lower peak hip extension angle than individuals without pain. ${ }^{51}$ However, the relationship between these movement-related parameters and other measures of hip-related pain (symptoms, function, quality of life, imaging and intra-articular findings) is unknown.

The evidence is limited, and conflicting, regarding differences in muscle activity between young and middle-aged active adults with hip-related pain and individuals without pain (online supplementary appendix). The evidence is also limited, and inconsistent, regarding differences in muscle size and adiposity of individual muscles in people with hip-related pain compared with those without (online supplementary appendix). To understand how movement-related parameters, including biomechanics and muscle function, may contribute to or result from symptoms, function, quality of life, imaging and intra-articular findings, future research should include measures of each of these parameters to identify the inter-relationships. The method of obtaining and grading imaging and intra-articular findings should be reported in future research on hip-related pain (Reiman et al, 2019). ${ }^{5}$

Research recommendation 3: Established minimum reporting standards for movement-related parameters (eg, biomechanics, muscle function) should be followed, or determined as appropriate.

The optimal methods for biomechanical and muscle function measurements are currently not established for individuals with hip-related pain, but this aim was beyond the scope of the current consensus meeting. We instead focused on the reporting of these measurements in the literature and found that the lack of consistent reporting limited the ability to critically appraise and reproduce previous studies, which also impeded their inclusion in meta-analyses (online supplementary appendix).

Currently, there are no reporting standards for biomechanical measures, although there are recommendations for methods of data collection. ${ }^{52}$ Despite established reporting standards for electromyographic data, ${ }^{53-55}$ reporting across studies remains poor (online supplementary appendix). For measurement of muscle size and adiposity, there are no reporting standards and the methods of measurement are inconsistent (online supplementary appendix). Thus, it is important that reporting standards should be followed (when available) and should be developed (when not available).

\section{Measures of physical activity and RTS}

Research recommendation 4: The patient's goals, expectations, physical activity and occupational requirements should be measured using quantitative and qualitative methods.

As discussed previously (clinical recommendation 5), quantifying patient expectations, and their fulfilment, regarding RTS, physical activity and occupational requirements is important to accurately interpret the efficacy of management of hip-related pain. It is equally important that these measures, in addition to patient satisfaction, be included in studies of interventions for hip-related pain. The IHiPRN participants also recommended in clinical recommendation 4 that physical activity be quantified using objective methods of measurement in people with hiprelated pain. This recommendation is equally relevant for hiprelated pain research as it is for clinical practice.

Research recommendation 5: The RTS continuum recommended by the 2016 RTS consensus paper should be used in future research.

Definitions used in studies examining RTS following management of hip-related pain often consider RTS as a dichotomous variable (yes/no) and fail to distinguish between the differing levels of RTS or consider whether the athlete has successfully returned to their preinjury sporting performance. ${ }^{56}$ Two recent studies have applied this graded definition, providing a more nuanced picture of RTS expectations for patients following hip arthroscopy. ${ }^{33} 35$ The 2016 consensus statement on RTS introduced the concept of RTS being considered a continuum through which an athlete progresses during the rehabilitation process. ${ }^{34}$ 
Three key elements of the RTS continuum were operationally defined as:

1. Return to participation: patient is able to participate in physical activity, even their preferred sport, but perhaps at a lower level, reduced workload or lower sporting performance.

2. RTS: the patient is able to return to their preferred sport but is not performing at their desired level.

3. Return to performance: the patient has returned to their preferred sport and is at or above their preinjury level with respect to performance and/or physical ability.

These principles of the RTS continuum are equally applicable for a patient with hip-related pain returning to any form of physical activity (including sport and occupational demands). By quantifying the patient's outcomes with respect to RTS, physical activity and/or occupational demands according to these three defined elements, the clinician and researcher can better determine whether management was successful at meeting the patient's expectations and goals. Accurate and detailed reporting of RTS using the continuum outlined in the 2016 RTS consensus paper $^{34}$ is therefore recommended for all future hip-related pain research. Specifically, reporting should include information regarding the patient's expectations and goals with respect to returning to physical activity (including sport and occupational demands), and their reasons for either returning to that physical activity or not.

Research recommendation 6: Future research is required to quantify, and report return to physical activity (including sport and occupation) following management of hip-related pain.

Six recent systematic reviews have examined RTS levels following surgical management of hip-related pain. The synthesis of these pooled findings determined that between $86 \%$ and $93 \%$ of athletes return to sport participation. ${ }^{49-60}$ However, the actual level of RTS of these athletes is mostly unreported, with only one-third of included studies clearly distinguishing RTS (any level) from RTS at preinjury level. ${ }^{56}$ Furthermore, there is limited to moderate evidence that one in four athletes did not return to their previous level of sport participation after surgery for FAI syndrome. ${ }^{56}$ Data from recent cross-sectional surveys of athletes afterhip arthroscopy suggest that the percentage of athletes returning to their preinjury level of sport with optimal performance could actually be as low as $17 \% .^{33} 35$ In general, poor outcome reporting on athletic performance after surgery makes it difficult to determine the actual sporting performance these athletes return to. ${ }^{56}$ Additionally, RTS following nonsurgical management of hip-related pain has only been reported in one study of eight football players, all of whom returned to playing at the same competitive level. ${ }^{61}$

The IHiPRN participants recommended that the return to physical activity (including sport and occupational demands) following hip-related pain management be quantified to improve the quality of reporting, and better understand patient outcomes.

Research recommendation 7: Research is recommended to determine the best criteria for rehabilitation progression and RTS following management of hip-related pain.

Several studies have reported RTS criteria following hip arthroscopy (online supplementary appendix). ${ }^{40-42} \quad 44-46 \quad 48$ However, there have been no reports of RTS criteria following non-surgical management of hip-related pain. There is also evidence that clinicians vary considerably in how they weight the importance of various outcome measures that may influence the RTS decision. ${ }^{62}$

Readiness to RTS should take into account the individual patient and the physical and psychological demands of the sport. ${ }^{34}$ Psychological readiness has rarely been considered in published data on RTS following hip surgery. Clearly, a significant gap exists in the literature with respect to standardised RTS criteria following management of hip-related pain, and this was identified as a future research priority by the IHiPRN participants.

\section{LIMITATIONS}

Several limitations require consideration regarding the clinical and research recommendations discussed in this manuscript. The group of participants who voted on these recommendations at the first IHiPRN meeting in Zurich included many different professions, somewhat represented sex diversity, although the numbers of men and women were not equal, and diversity in research and clinical experts. However, due to the invitation process and budgetary and logistical limitations, the group cannot be considered fully inclusive. Therefore, the contributions were limited to the participants who were part of the consensus process. Furthermore, due to logistical limitations patients were not included in the consensus process. Patients living with hip pain can provide an important perspective to enhance the agreement process and their involvement will be considered for future consensus meetings.

The operational definitions and nomenclature used for hiprelated pain have been substantially heterogeneous. ${ }^{2} 18$ Consequently, widespread variability in diagnostic terminology and classification systems in the published literature made it difficult to synthesise the findings of research in this area. Therefore, the systematic reviews and studies used to inform consensus likely contain a wide range of diagnostic parameters and participants. Standardisation of classification systems in future hip-related pain research may result in different findings and recommendations.

This consensus paper is based only on English language studies; studies of importance written in other languages may have been excluded. Quality assessment of the included studies was not performed; rather interpretation of study quality was inferred from the included systematic reviews when available. Therefore, the quality of evidence presented to the IHiPRN participants and on which they based their voting is limited by the quality of the studies included.

\section{CONCLUSION}

The first IHiPRN consensus meeting was held in Zurich, Switzerland, in November 2018. At this meeting, 38 clinical research experts in hip-related pain discussed and voted on recommendations relating to standardised measurement of physical capacity in people with hip-related pain. Four key areas were considered: (1) clinical measures (range of motion, muscle strength, functional impairments), (2) laboratory-based measures (biomechanics and muscle function (muscle activity, size and adiposity)), (3) physical activity, and (4) RTS/performance. The IHiPRN participants developed and gained consensus on six clinical recommendations and seven research recommendations, all of which were an amalgamation of best available evidence and expert opinion. Clinicians and researchers can use these recommendations to guide their choice of measurement methods in the investigation and management of patients with hip-related pain. The research recommendations highlight current gaps in the literature and will assist in prioritising future research on hip-related pain.

\section{Author affiliations}

${ }^{1}$ La Trobe Sport and Exercise Medicine Research Centre, School of Allied Health, Human Services and Sport, College of Science, Health and Engineering, La Trobe University, Melbourne, Victoria, Australia 
${ }^{2}$ School of Health and Rehabilitation Sciences, University of Queensland, St Lucia, Queensland, Australia

${ }^{3}$ Human Performance Lab, Schulthess Clinic, Zurich, Switzerland

${ }^{4}$ Laboratory of Exercise and Health, ETH, Zurich, Switzerland

${ }^{5}$ Department of Health Sciences, Lund University, Lund, Sweden

${ }^{6}$ Sports Orthopedic Research Center-Copenhagen (SORC-C), Department of

Orthopedic Surgery, Copenhagen University Hospital, Amager-Hvidovre, Denmark

Department of Health Sciences, Lund University, Lund, Sweden

${ }^{8}$ Griffith Centre of Biomedical and Rehabilitation Engineering (GCORE), Menzies

Health Institute Queensland Griffith University, School of Allied Health Sciences, Gold

Coast, Queensland, Australia

${ }^{9}$ Department of Physical Therapy, University of British Columbia, Vancouver, British

Columbia, Canada

${ }^{10}$ Division of Physical Therapy, The Ohio State University, Columbus, Ohio, USA

${ }^{11}$ Orthopedic Surgery, Duke University Medical Center, Durham, North Carolina, USA

${ }^{12}$ University of Canberra Research into Sport and Exercise (UCRISE), University of

Canberra, Canberra, Australian Capital Territory, Australia

${ }^{13}$ Monash School of Medicine, Melbourne, Victoria, Australia

${ }^{14}$ Department of Orthopaedics, Schulthess Klinik, Zürich, Switzerland

${ }^{15}$ Schulthess Clinic Human Performance Lab, Zurich, Switzerland

${ }^{16}$ Family Practice and Kinesiology, The University of British Columbia, Vancouver,

British Columbia, Canada

${ }^{17}$ Department of Orthopaedic Surgery, University Medical Centre Rotterdam,

Rotterdam, The Netherlands

${ }^{18}$ Physical Therapy, Washington University School of Medicine in St Louis, St Louis, Missouri, USA

${ }^{19}$ Orthopaedic Surgery, Washington University School of Medicine in St Louis, Saint Louis, Missouri, USA

${ }^{20}$ ASPETAR Orthopedic and Sports Medicine Hospital, Doha, Qatar

${ }^{21}$ Department of Continuing Education, University of Oxford, Oxford, UK

${ }^{22}$ Warwick Orthopaedics, University of Warwick, Coventry, UK

${ }^{23}$ Warwick Medical School, University of Warwick, Coventry, UK

${ }^{24}$ Sports Medicine, SportAdo consultation, University Hospital of Lausanne (CHUV)

Multidisciplinary Unit of Adolescent Health, Lausanne, Switzerland

${ }^{25}$ Faculty of Health, University of Technology Sydney, Sydney, New South Wales, Australia

${ }^{26}$ Elite Sports Imaging, SL, Madrid, Spain

${ }^{27}$ Division of Orthopedic Surgery, Oslo University Hospital, Oslo, Norway

${ }^{28}$ The Australian Ballet, Southbank, Victoria, Australia

${ }^{29}$ Oslo Sports Trauma Research Center, Oslo, Norway

${ }^{30}$ Department of Sport Medicine, Norwegian School of Sport Sciences, Oslo, Norway

${ }^{31}$ Division of Orthopedic Surgery, Oslo University Hospital, Oslo, Norway

${ }^{32}$ Physical Therapy and Athletic Training, Boston University, Boston, Massachusetts, USA

Correction notice This article has been corrected since it published Online First. The author details have been amended.

Twitter Andrea Britt Mosler @AndreaBMosler, Joanne Kemp @JoanneLKemp, Matthew King @mattgmking1, Peter R Lawrenson @PeteLawrenson, Adam Semciw @ASemciw, Nicola C Casartelli @NicCasartelli, Tobias Wörner @Wuninho, Lasse Ishøi @Lasselshoei, Eva Ageberg @EvaAgeberg, Laura E Diamond @lauradiamond05, Stephanie Di Stasi @S_DiStasi, Michael P Reiman@MikeReiman, Michael Drew @_mickdrew, Daniel Friedman @ddfriedman, Kristian Thorborg @KThorborg, Rintje Agricola @RintjeAgricola, Hendrik Paul Dijkstra @DrPaulDijkstra, Damian Griffin @DamianGriffin, Boris Gojanovic @drsportsante, Marcie Harris-Hayes @MHarrisHayes, Joshua J Heerey @JHeerey, Franco M Impellizzeri @francoimpell, Ara Kassarjian @akassarjian, Håvard Moksnes@HMoksnes, Mark J Scholes @MarkScholes85, Andreas Serner @aserner and Cara L Lewis @ProfCaraLewis

Contributors All authors were fully involved in the preparation and completion of the manuscript. Each author has read and concurs with the content in this manuscript. This material has not and will not be submitted for publication elsewhere.

Funding ABM is supported by NHMRC (Australia; ECF 1156674).

Competing interests None declared.

Patient consent for publication Not required.

Provenance and peer review Not commissioned; externally peer reviewed.

ORCID iDs

Andrea Britt Mosler http://orcid.org/0000-0001-7353-2583

Joanne Kemp http://orcid.org/0000-0002-9234-1923

Matthew King http://orcid.org/0000-0003-0470-5924

Peter R Lawrenson http://orcid.org/0000-0002-6479-6840

Nicola C Casartelli http://orcid.org/0000-0002-1280-866X

Tobias Wörner http://orcid.org/0000-0001-5555-0876

Lasse Ishøi http://orcid.org/0000-0002-2716-6567
Eva Ageberg http://orcid.org/0000-0002-8639-3006

Laura E Diamond http://orcid.org/0000-0002-2197-1856

Stephanie Di Stasi http://orcid.org/0000-0001-6302-4147

Michael P Reiman http://orcid.org/0000-0003-4557-3446

Kristian Thorborg http://orcid.org/0000-0001-9102-4515

Karim M Khan http://orcid.org/0000-0002-9976-0258

Kay M Crossley http://orcid.org/0000-0001-5892-129X

Boris Gojanovic http://orcid.org/0000-0001-5075-9371

Marcie Harris-Hayes http://orcid.org/0000-0003-4274-1651

Joshua J Heerey http://orcid.org/0000-0001-8691-1830

Franco M Impellizzeri http://orcid.org/0000-0002-1703-2573

Kristian Marstrand Warholm http://orcid.org/0000-0003-0978-0667

Mark J Scholes http://orcid.org/0000-0001-9216-1597

Andreas Serner http://orcid.org/0000-0003-4308-901X

Cara L Lewis http://orcid.org/0000-0002-9888-4902

\section{REFERENCES}

1 Filbay SR, Kemp JL, Ackerman IN, et al. Quality of life impairments after hip arthroscopy in people with hip chondropathy. J Hip Preserv Surg 2016;3:154-64.

2 Griffin DR, Dickenson EJ, O'Donnell J, et al. The Warwick agreement on femoroacetabular impingement syndrome (FAl syndrome): an international consensus statement. Br J Sports Med 2016;50:1169-76.

3 Kemp JL, Makdissi M, Schache AG, et al. Is quality of life following hip arthroscopy in patients with chondrolabral pathology associated with impairments in hip strength or range of motion? Knee Surg Sports Traumatol Arthrosc 2016;24:3955-61.

4 Kemp JL, Coburn SL, Jones DM, et al. The physiotherapy for femoroacetabular impingement rehabilitation study (physioFIRST): a pilot randomized controlled trial. J Orthop Sports Phys Ther 2018:48:307-15.

5 Reiman MP, Agricola R, Kemp JL. Consensus recommendations on the classification, definition and diagnostic criteria of hip-related pain in young and middle-aged active adults from the International Hip-related pain research network, Zurich. Br I Sports Med. 2020:54:631-41.

6 Moradi-Lakeh M, Forouzanfar MH, Vollset SE, et al. Burden of musculoskeletal disorders in the eastern Mediterranean region, 1990-2013: findings from the global burden of disease study 2013. Ann Rheum Dis 2017;76:1365-73.

7 Delahunt E, Thorborg K, Khan KM, et al. Minimum reporting standards for clinical research on groin pain in athletes. Br J Sports Med 2015;49:775-81.

8 Diamond LE, Dobson FL, Bennell KL, et al. Physical impairments and activity limitations in people with femoroacetabular impingement: a systematic review. $\mathrm{Br}\rfloor$ Sports Med 2015;49:230-42.

9 Freke MD, Kemp J, Svege I, et al. Physical impairments in symptomatic femoroacetabular impingement: a systematic review of the evidence. $\mathrm{Br}$ I Sports Med 2016:50:1180

10 Tak I, Engelaar L, Gouttebarge V, et al. Is lower hip range of motion a risk factor for groin pain in athletes? A systematic review with clinical applications. Br J Sports Med 2017; 51:1611-21.

11 Mosler AB, Agricola R, Weir A, et al. Which factors differentiate athletes with hip/groin pain from those without? A systematic review with meta-analysis. Br J Sports Med 2015;49:810-21.

12 Whittaker JL, Small C, Maffey L, et al. Risk factors for groin injury in sport: an updated systematic review. Br I Sports Med 2015;49:803-9.

13 Whittaker JL, Booysen N, de la Motte S, et al. Predicting sport and occupational lower extremity injury risk through movement quality screening: a systematic review. $\mathrm{Br} J$ Sports Med 2017;51:580-5.

14 Crossley KM, Stefanik JJ, Selfe J, et al. Patellofemoral pain consensus statement from the 4th International Patellofemoral pain research retreat, Manchester. Part 1: terminology, definitions, clinical examination, natural history, patellofemoral osteoarthritis and patient-reported outcome measures. Br I Sports Med 2016;2016:839-43

15 Collins NJ, Barton CJ, van Middelkoop M, et al. Consensus statement on exercise therapy and physical interventions (orthoses, taping and manual therapy) to treat patellofemoral pain: recommendations from the 5 th International Patellofemoral pain research retreat, gold Coast, Australia, 2017. Br J Sports Med 2018:2018:1170-8.

16 Kloskowska P, Morrissey D, Small C, et al. Movement patterns and muscular function before and after onset of sports-related groin pain: a systematic review with metaanalysis. Sports Med 2016;46:1847-67.

17 Pacheco-Carrillo A, Medina-Porqueres I. Physical examination tests for the diagnosis of femoroacetabular impingement. A systematic review. Physical Therapy in Sport 2016:21:87-93.

18 Weir A, Brukner P, Delahunt E, et al. Doha agreement meeting on terminology and definitions in groin pain in athletes. Br J Sports Med 2015;49:768-74.

19 Mayne E, Memarzadeh A, Raut P, et al. Measuring hip muscle strength in patients with femoroacetabular impingement and other hip pathologies. Bone Joint Res 2017;6:66-72

20 Dobson F, Choi YM, Hall M, et al. Clinimetric properties of observer-assessed impairment tests used to evaluate hip and groin impairments: a systematic review. Arthritis Care Res 2012;64:1565-75. 
21 Thorborg K, Bandholm T, Hölmich P. Hip- and knee-strength assessments using a hand-held dynamometer with external belt-fixation are inter-tester reliable. Knee Surg Sports Traumatol Arthrosc 2013;21:550-5.

22 Kivlan BR, Martin RL. Functional performance testing of the hip in athletes: a systematic review for reliability and validity. Int J Sports Phys Ther 2012;7:402-12.

23 Gribble PA, Hertel J, Plisky P. Using the StAR excursion balance test to assess dynamic Postural-Control deficits and outcomes in lower extremity injury: a literature and systematic review. J Athl Train 2012;47:339-57.

24 King MG, Lawrenson PR, Semciw Al, et al. Lower limb biomechanics in femoroacetabular impingement syndrome: a systematic review and meta-analysis. $\mathrm{Br} J$ Sports Med 2018;52:566-80

25 Kapteyn A, Banks J, Hamer M, et al. What they say and what they do: comparing physical activity across the USA, England and the Netherlands. J Epidemiol Community Health 2018;72:471-6.

26 Arnold JB, Walters JL, Ferrar KE. Does physical activity increase after total hip or knee arthroplasty for osteoarthritis? A systematic review. J Orthop Sports Phys Ther 2016;46:431-42.

27 Evenson KR, Goto MM, Furberg RD. Systematic review of the validity and reliability of consumer-wearable activity trackers. Int J Behav Nutr Phys Act 2015:12.

28 Jacobsen JS, Thorborg K, Hölmich P, et al. Does the physical activity profile change in patients with hip dysplasia from before to 1 year after periacetabular osteotomy? Acta Orthop 2018;89:622-7.

29 Sliepen M, Brandes M, Rosenbaum D. Current physical activity monitors in hip and knee osteoarthritis: a review. Arthritis Care Res 2017:69:1460-6.

30 Crizer MP, Kazarian GS, Fleischman AN, et al. Stepping toward objective outcomes: a prospective analysis of step count after total joint arthroplasty. J Arthroplasty 2017;32:S162-5.

31 Harding P, Holland AE, Delany C, et al. Do activity levels increase after total hip and knee arthroplasty? Clin Orthop Relat Res 2014;472:1502-11.

32 Feehan LM, Geldman J, Sayre EC, et al. Accuracy of Fitbit devices: systematic review and narrative syntheses of quantitative data. JMIR Mhealth Uhealth 2018;6.

33 Ishøi L, Thorborg K, Kraemer O, et al. Return to sport and performance after hip arthroscopy for femoroacetabular impingement in 18- to 30-year-old athletes: a cross-sectional cohort study of 189 athletes. Am J Sports Med 2018;46:2578-87.

34 Ardern CL, Glasgow P, Schneiders A, et al. 2016 consensus statement on return to sport from the first world Congress in sports physical therapy, Bern. Br J Sports Med 2016;50:853-64.

35 Wörner T, Thorborg K, Stålman A, et al. High or low return to sport rates following hip arthroscopy is a matter of definition? Br J Sports Med 2018;52:1475-6.

36 Mannion AF, Impellizzeri FM, Naal FD, et al. Fulfilment of patient-rated expectations predicts the outcome of surgery for femoroacetabular impingement. Osteoarthritis and Cartilage 2013;21:44-50.

37 Palazzo C, Jourdan C, Descamps S, et al. Determinants of satisfaction 1 year after total hip arthroplasty: the role of expectations fulfilment. BMC Musculoskelet Disord 2014; 15 .

38 Hoffmann TC, Del Mar C. Patients' Expectations of the Benefits and Harms of Treatments, Screening, and Tests. JAMA Intern Med 2015;175:274.

39 Mannion $A F$, Junge $A$, Elfering $A$, et al. Great expectations: really the novel predictor of outcome after spinal surgery? Spine 2009;34:1590-9.

40 Wahoff M, Ryan M. Rehabilitation after hip femoroacetabular impingement arthroscopy. Clin Sports Med 2011;30:463-82.

41 Edelstein J, Ranawat A, Enseki KR, et al. Post-Operative guidelines following hip arthroscopy. Curr Rev Musculoskelet Med 2012;5:15-23.

42 Garrison JC, Osler MT, Singleton SB. Rehabilitation after arthroscopy of an acetabular Labral tear. North Am J Sports Phys Ther NAJSPT 2007:2:241-50.
43 Voight ML, Robinson K, Gill L, et al. Postoperative rehabilitation guidelines for hip arthroscopy in an active population. Sports Health 2010;2:222-30.

44 Wahoff M, Dischiavi S, Hodge J, et al. Rehabilitation after labral repair and femoroacetabular decompression: criteria-based progression through the return to sport phase. Int J Sports Phys Ther 2014;9:813-26.

45 Pierce CM, LaPrade RF, Wahoff M, et al. Ice hockey Goaltender rehabilitation, including On-Ice progression, after arthroscopic hip surgery for femoroacetabular impingement. J Orthop Sports Phys Ther 2013;43:129-41.

46 Kuhns BD, Weber $A E$, Batko $B$, et al. A four-phase physical therapy regimen for returning athletes to sport following hip arthroscopy for femoroacetabular impingement with routine capsular closure. Int J Sports Phys Ther 2017;12:683-96.

47 Domb BG, Stake CE, Finch NA, et al. Return to sport after hip arthroscopy: aggregate recommendations from high-volume hip arthroscopy centers. Orthopedics 2014;37:e902-5.

48 Grzybowski JS, Malloy P, Stegemann C, et al. Rehabilitation Following Hip Arthroscopy - A Systematic Review. Front Surg 2015;2.

49 O'Connor M, Minkara AA, Westermann RW, et al. Return to play after hip arthroscopy: a systematic review and meta-analysis. Am J Sports Med 2018;46:2780-8.

50 Reichenbach $S$, Jüni $P$, Nüesch $E$, et al. An examination chair to measure internal rotation of the hip in routine settings: a validation study. Osteoarthritis and Cartilage 2010;18:365-71.

51 Xu C, Wen X, Wei W, et al. Gait parameters associated with untreated developmental dysplasia of the hip: a systematic review; 11 .

52 Baker R. ISB recommendation on definition of joint coordinate systems for the reporting of human joint motion-part I: ankle, hip and spine. J Biomech 2003:36:300-2.

53 Hermens HJ, Freriks B, Disselhorst-Klug C, et al. Development of recommendations for SEMG sensors and sensor placement procedures. J Electromyogr Kinesiol 2000;10:361-74

54 Merletti R. Standards for reporting EMG data. J Electromyogr Kinesio/ 2017;32:I-II.

55 Merletti R, Hermens H, Kadefors R. European Community Projects on Surface Electromyography. In: 2001 Conference Proceedings of the 23rd Annual International Conference of the IEEE Engineering in Medicine and Biology Society. Istanbul, Turkey: IEEE, 2001: 1119-22.

56 Reiman MP, Peters S, Sylvain J, et al. Femoroacetabular impingement surgery allows $74 \%$ of athletes to return to the same competitive level of sports participation but their level of performance remains unreported: a systematic review with metaanalysis. Br J Sports Med 2018;52:972-81.

57 Memon M, Kay J, Hache P, et al. Athletes experience a high rate of return to sport following hip arthroscopy. Knee Surg Sports Traumatol Arthrosc 2019;27:3066-104.

58 Lovett-Carter D, Jawanda AS, Hannigan A. Meta-Analysis of the surgical and rehabilitative outcomes of hip arthroscopy in athletes with femoroacetabular impingement. Clin J Sport Med 2018;1.

59 Kierkegaard S, Langeskov-Christensen M, Lund B, et al. Pain, activities of daily living and sport function at different time points after hip arthroscopy in patients with femoroacetabular impingement: a systematic review with meta-analysis. $\mathrm{Br} J$ Sports Med 2017;51:572-9.

60 Casartelli NC, Leunig M, Maffiuletti NA, et al. Return to sport after hip surgery for femoroacetabular impingement: a systematic review. Br J Sports Med 2015:49:819-24.

61 Feeley BT, Powell JW, Muller MS, et al. Hip injuries and Labral tears in the National football League. Am J Sports Med 2008;36:2187-95.

62 Wörner T, Thorborg K, Moksnes H, et al. Similar views on rehabilitation following hip arthroscopy among physiotherapists and surgeons in Scandinavia: a specialized care survey. Knee Surg Sports Traumatol Arthrosc 2018:26:2519-26. 